\title{
PENGARUH BRAND IMAGE DAN E-SERVICE QUALITY TERHADAP CUSTOMER SATISFACTION BENTUK INOVASI PEMASARAN BUKALAPAK
}

\author{
Euis Bandawaty \\ Universitas Pendidikan Indonesia \\ euisbandawaty@upi.edu \\ Ratih Huriyati \\ Universitas Pendidikan Indonesia \\ ratih@upi.edu \\ Puspo Dewi Dirgantari \\ Universitas Pendidikan Indonesia \\ puspodewi@upi.edu
}

Suggested Citation:

Chen, M. (2007). Consumer attitudes and purchase intentions in relation to organic foods in Taiwan: Moderating
$\begin{aligned} & \text { effects of food-related personality traits. Food Quality and Preference, 18, } 1008-1021 . \\ & \text { http://doi.org/10.1016/i.foodqual.2007.04.004 }\end{aligned}$

Abstract:

The purpose of this study are to analyze marketing innovation from the influence of brand image and e-service quality on customer satisfaction of Bukalapak. The type of this research is quantitative. The data source of this research is primary data by taking a sample of Bukalapak customers. Data collection was carried out using accidental sampling by distributing to 100 Bukalapak customer respondents. The findings of this study indicate that brand image and e-service quality significantly influence Bukalapak customer satisfaction. The novelty of the results of this research is that custumer satisfaction is influenced by the brand image indicator, namely the uniqueness of the goods offered that has a sustainable advantage and an indicator of e-service quality that lies in compensation in terms of the speed of handling in case of problems

Keywords: brand image, customer satisfaction, e-service quality

Abstrak:

Tujuan dari penelitian ini adalah untuk menganalisis inovasi pemasaran dari pengaruh brand image dan e-service quality terhadap customer satisfaction Bukalapak. Jenis penelitian pada penelitian ini adalah kuantitatif. Sumber data penelitian ini merupakan data primer dengan mengambil sampel pelanggan Bukalapak. Pengumpulan data dilakukan menggunakan accidental sampling dengan menyebarkan kepada 100 responden pelanggan Bukalapak. Hasil temuan dari penelitian ini menunjukkan bahwa brand image dan e-service quality berpengaruh secara signifikan terhadap customer satisfaction Bukalapak. Novelti dari hasil penlitian ini bahwa custumer satisfaction di pengaruhi oleh indikator brand image yaitu keunikan barang yang di tawarkan yang memiliki keunggulan yang berkelanjutan dan indikator dari e-service quality yang terletak pada kompensasi dalam hal cepatnya penanganan apabila terjadi masalah.

Kata kunci brand image, customer satisfaction, e-service quality

JEL Classification: M30, M31 


\section{Pendahuluan}

E-commerce atau yang biasa disebut perdagangan elektronik adalah penyebaran, pembelian, penjualan, pemasaran barang dan jasa melalui sistem elektronik terutama internet dan media sosial. Pemasaran malalui ecommerce merupakan jenis pemasaran yang inovatif yang menjadi peluang bagi para pelaku usaha dalam mengembangkan produk dan pelayanan, serta sistem distribusi untuk menjaring pelanggan agar mengenal dan membeli brand yang ditawarkan. Menurut Laudon dan Laudon (2008) e-commerce adalah suatu proses membeli dan menjual produk-produk secara elektronik oleh konsumen dan perusahaan ke perusahaan dengan komputer sebagai perantara transaksi bisnis. Menurut Peter dan Olson (2013) perdagangan elektronik atau e-commerce adalah proses dimana menganalisis inovasi pemasaran dari pengaruh brand image dan e-service quality terhadap customer satisfaction Bukalapak terhadap pembeli dan penjual dalam melakukan pertukaran informasi, uang dan barang melalui sarana elektronik, terutama di internet.

Pemarasan e-commerce memungkinkan antara penjual dan pembeli dalam melakukan transaksi tidak perlu bertatap muka karena semua aktivitas dapat dilakukan melalui media internet. Inovasi ini dimanfaatkan sebagai sarana penjualan berbagai produk. Banyak manfaat yang dapat diperoleh dengan aktivitas e-commerce antara lain menghemat waktu dan biaya distribusi, mempermudah proses mencari dan membandingkan produk sehingga mendapatkan produk sesuai dengan kebutuhan.

Semakin hari semakin banyak orang yang akhirnya memutuskan untuk memasarkan produk melalui ecommerce. Baik itu melalui situs web maupun media sosial. Sulianta (2012) menjelaskan empat faktor yang mendukung perkembangan pemasaran melalui e-commerce. Pertama, Ada beragam fasilitas internet yang dapat dimanfaatkan sebagai lahan usaha. Fasilitas yang dimaksud ini adalah media sosial, platform khusus untuk berjualan seperti Lazada, tokopedia, bukalapak, blibli, olx dan shopee. Selain itu para pelaku usaha juga bisa memiliki situs web sendiri untuk produk yang diperdagangkannya. Bahkan kini fasilitas lahan usaha, khususnya untuk bisnis kuliner, sudah merambah ke berbagai aplikasi transportasi seperti Go-Food dan GrabFood. Ada juga Go- Shop, Go-Mart, Go-Med, dan Grab Groceries.

Kedua, penyedia jasa pihak ketiga sebagai pengantar produk kepada pelanggan. Kini sudah banyak jasa kurir yang siap mengantarkan produk yang konsumen pesan melalui internet. Untuk pengiriman ke dalam atau ke luar kota dan luar negeri bisa menggunakan jasa Pos, JNE, J\&T Express, dan lain-lain. Apabila menggunakan jasa kurir tersebut dirasakan terlalu lama, sedangkan pelanggan yang membutuhkan produk saat ini juga, selama masih di kota yang sama, dapat mengirimkannya dengan menggunakan aplikasi transportasi yaitu GoSend dan Grab Delivery.

Ketiga, adanya penyedia jasa pembuatan situs web untuk usaha. Dengan meningkatnya kebutuhan orang untuk memasarkan produk melalui e-commerce, maka muncul juga orang yang menyediakan jasa membuat situs web bisnis. Seseorang hanya perlu menyampaikan template yang diinginkan pada situs web dan setelah situs web tersebut jadi maka dia dapat langsung menggunakannya untuk memasarkan produk. Jika adanya keterbatasan dalam hal modal, maka pelaku usaha dapat memanfaatkan media sosial seperti facebook dan instagram. Terakhir, meningkatnya kepercayaan konsumen untuk berbelanja online. Belanja online tidak lagi menjadi hal yang tabu untuk dilakukan. Bagi calon konsumen yang tidak memiliki waktu atau tidak suka pergi untuk berbelanja dapat menggunakan laptop atau smartphone saja. Hal ini tentu menjadi keuntungan bagi orang yang ingin memasarkan produk melalui e-commerce. Selain itu ketika konsumen sudah merasa puas dengan pengalamannya berbelanja melalui situs web atau media sosial, maka bukan tidak mungkin mereka akan melakukan transaksi lagi di lain waktu.

Perkembangan e-commerce didukung oleh jumlah pengguna internet yang mencapai sekitar $30 \%$ dari total penduduk di Indonesia. Menkominfo menyebutkan bahwa nilai transaksi e-commerce pada tahun 2019 naik 31\% yaitu menjadi US\$3.8 milyar, yang didorong tingginya populasi dan pertumbuhan ekonomi, meluasnya penetrasi telepon pintar, serta makin banyanya produk yang dijual pelaku usaha e-commerce.

Salah satu perusahaan e-commerce yang sedang berkembang di Indonesia adalah PT. Bukalapak.com (selanjutnya disebut Bukalapak). Bukalapak didirikan pada tahun 2010 yang oleh Achmad Zacky. Bukalapak menyediakan sarana penjualan dari konsumen kepada konsumen dimanapun dan siapapun dapat membuka toko online untuk melayani calon pembeli dari seluruh Indonesia.

Berdasarkan data Top Brand Award pada tahun 2018 di bawah ini dapat dilihat bahwa Bukalapak menempati peringkat ketiga sebesar $7,9 \%$. Bukalapak masih kalah dengan situs jual beli online lainnya yaitu Lazada dan Tokopedia. Hal ini menunjukkan bahwa pentingnya kepuasan pelanggan (customer satisfaction) agar Bukalapak bisa lebih unggul dari situs jual beli online lainnya. 
Tabel 1. Top Brand Situs Jual Beli Online di Indonesia Tahun 2018

\begin{tabular}{ccc}
\hline Merek & TBI & TOP \\
\hline Lazada.co.id & $47.5 \%$ & TOP \\
Tokopedia.com & $10.8 \%$ & TOP \\
Bukalapak.com & $7.9 \%$ & \\
Blibli.com & $6.8 \%$ & \\
Olx.co.id & $6.6 \%$ & \\
\hline
\end{tabular}

Sumber : (www.topbrand-award.com, 2018)

Kepuasan pelanggan sangat dipengaruhi oleh brand image dan e-service quality. Pelayanan yang tidak memuaskan akan membuat pelanggan kecewa dan berdampak buruk terhadap brand image. Jika kualitas pelayanan tidak diperbaiki, maka brand image perusahaan akan terus menurun sehingga membuat konsumen tidak akan menggunakan produk dari perusahaan. Dengan demikian pelayanan yang berkualitas berperan penting dalam mewujudkan kepuasan pelanggan (customer satisfaction).

Menurut Lovelock (2010) layanan online yang berkualitas melibatkan bukan hanya interaksi dengan sebuah situs, tetapi harus memperhatikan kualitas proses yang akan berpengaruh terhadap kualitas hasil. Semua tahap harus dievaluasi untuk mendapatkan kualitas pelayanan yang terbaik bagi pelanggan. Pelaku usaha online perlu mengevaluasi setiap tanggapan pelanggan, menjawab pertanyaan pelanggan, berempati terhadap pelanggan, dan memberikan tanggapan yang cepat dengan didukung dengan data yang akurat.

Persaingan di dalam industri e-commerce sangat ketat, seperti Bukalapak yang menerapkan konsep C2C (Customer to Customer) bukan lagi berorientasi kepada cara meningkatkan volume penjualan tetapi lebih berorientasi untuk memuaskan kebutuhan pelanggan dan menciptakan loyalitas pelanggan. Kepuasan pelanggan merupakan kunci dalam menciptakan loyalitas pelanggan (Kotler dan Armstrong 2008).

Tingkat persaingan yang tinggi memberikan peluang kepada pelanggan untuk memilih berbagai alternatif produk, harga, saluran distribusi. Hanya produk yang berkualitas yang akan menjadi pilihan pelanggan (Kotler 2005). Sementara itu kualitas produk yang rendah akan menimbulkan ketidakpuasan pelanggan. Pelanggan yang kecewa karena harapannya tidak terpenuhi dapat menimbulkan kerugian yang lebih besar bagi perusahaan karena pelanggan tersebut secara spontanitas akan bercerita tentang kekecewaannya paling sedikit kepada 15 orang lainnya (Lupiyoadi dan Hamdani 2006).

Dengan demikian upaya perbaikan kualitas layanan maupun kualitas produk akan jauh lebih efektif bagi kesinambungan perusahaan. Berdasarkan penjelasan di atas, dapat disimpulkan beberapa permasalahan mendasar yaitu apakah Brand image dan E-service quality dapat berpengaruh untuk meningkatkan Customer Satisfaction Bukalapak. Beberapa penelitian terdahulu yang dilakukan oleh Christian Lasander (2013) dengan judul "Citra Merek, Kualitas Produk dan Promosi Pengaruhnya Terhadap Kepuasan Konsumen Pada Makanan Tradisional", pada penelitian tersebut, variabel yang diteliti meliputi $X_{1}$ : Citra Merek, $X_{2}$ : Kualitas Produk, $X_{3}$ : Promosi, dan Y: Kepuasan Konsumen. Metode penelitian: Regresi Liner Berganda, Hasil penelitian: a. Citra merek berpengaruh positif dan signifikan terhadap kepuasan konsumen; $b$. Kualitas produk berpengaruh positif dan signifikan terhadap kepuasan konsumen; c. Promosi berpengaruh positif dan signifikan terhadap kepuasan konsumen.

Penelitian lainnya yaitu yang dilakukan oleh Malik, dkk. (2012) dengan judul Impact of Brand Image, Service Quality and Price on Customer Satisfaction in Pakistan Telecommunication Sector. Variabel yang diteliti meliputi: $\mathrm{X}_{1}$ : Brand Image; $\mathrm{X}_{2}$ : Service Quality; $\mathrm{X}_{3}$ : Price, dan Y: Customer Satisfaction, Metode Penelitian: Regresi Linier Berganda, Hasil Penelitian: a. Brand image berpengaruh positif dan signifikan terhadap customer satisfaction; b.Service quality berpengaruh positif dan signifikan terhadap customer satisfaction; $c$. Price berpengaruh positif dan signifikan terhadap customer satisfaction. Berdasarkan paparan tersebut, penelitian ini bertujuan untuk menganalisis inovasi pemasaran dari pengaruh brand image dan e- service quality terhadap customer satisfaction Bukalapak. 


\section{Metode Penelitian}

Metode penentuan sampel yang digunakan adalah dengan menggunakan metode pemilihan sampel secara non-probabilitas (non-probability sampling methods). Penentuan sampel dalam penelitian ini dilakukan secara accidental sampling atau convenience sampling, yaitu cara mengumpulkan informasi dari elemen-elemen populasi yang tersedia dengan tidak perlu susah payah (Sarwoko, 2007:19). Peneliti memilih individu terdekat untuk dijadikan sebagai sampel penelitian sampai ukuran sampel yang diinginkan tercapai dan memilih individu yang ada di tempat dan dapat diakses selama waktu penelitian (Cohen, Manion, \& Morrison, 2007:36). Dari hasil perhitungan, sampel yang didapat yaitu sebesar 96,04 untuk lebih memudahkan maka dibulatkan menjadi 100 responden. Jadi penelitian ini menggunakan 100 responden untuk dijadikan sampel penelitian.Dalam mengumpulkan data penulis menggunakan beberapa metode pengumpulan data berupa angket (kuesioner) yaitu membuat daftar pertanyaan atau kuesioner yang dibagikan kepada responden, data yang terkumpul ditabulasi dengan menggunakan Skala Likert.

\section{Hasil Penelitian}

Berdasarkan hasil input data ke dalam proses pengolahan data, maka diperoleh hasil regresi pada tabel di bawah ini :

Tabel 1. Hasil Uji Regresi (Uji T)

\begin{tabular}{|l|c|c|c|c|c|}
\hline \multirow{2}{*}{ Model } & \multicolumn{2}{|c|}{ Unstandardized Coefficients } & Standardized & \multirow{2}{*}{ T-value } & Sig. \\
\cline { 2 - 3 } 1 (constant) & B. & Std. Error Beta & Coefficients & & .995 \\
Brand Image (X1) & .128 & 2.274 & & 0.56 & .000 \\
E-Service Quality (X2) & .416 & .071 & .470 & 5.839 & .000 \\
\hline
\end{tabular}

Sumber : Data Diolah (2020)

Dari Uji Regresi Berganda di atas dapat dirumuskan suatu persamaan regresi untuk mengetahui pengaruh brand image dan e-service quality terhadap customer satisfaction sebagai berikut:

$$
\begin{aligned}
& Y=a+\beta 1 X 1+\beta 2 X 2+e \\
& Y=0.128+0.416 X 1+0.319 X 2+e
\end{aligned}
$$

Persamaan regresi linear berganda tersebut dapat diartikan sebagai berikut:

a. Konstanta sebesar 0.128 menyatakan bahwa jika independent variable dianggap konstan, maka Customer Satisfaction sebesar 0.128

b. Koefisien regresi Brand Image sebesar 0.416 menyatakan bahwa setiap Brand Image mengalami kenaikan satu unit maka Customer Satisfaction ikut mengalami kenaikan sebesar 0.416. Pada kolom signifikansi menunjukkan bahwa Brand Image memiliki pengaruh signifikan dimana nilai signifikansi yang diperoleh adalah $0,000<0,05$.

c. Koefisen regresi E-Service Quality sebesar 0.319 menyatakan bahwa setiap Eservice Quality mengalami kenaikan satu unit maka Customer Satisfaction ikut mengalami kenaikan sebesar 0.319. Pada kolom signifikansi menunjukkan bahwa E-Service Quality memiliki pengaruh signifikan dimana nilai signifikansi yang diperoleh adalah $0,000<0,05$.

Berdasarkan hasil uji $F$, nilai $F$ hitung diperoleh sebesar 136.595 sedangkan nilai $F$ tabel sebesar 3,09 maka dapat diketahui nilai $F$ hitung $136.595>F$ tabel 3,09 dan nilai probabilitas signifikan 0,000 lebih kecil dari 0,05. Maka model regresi ini dapat dipakai untuk customer satisfaction. Dengan kata lain dapat dikatakan bahwa variabel brand image dan e-service quality berpengaruh signifikan secara bersama-sama (simultan) terhadap variabel customer satisfaction. Selanjutnya, hasil analisis Koefisien Determinasi yang menunjukkan nilai Adjusted R Square sebesar 0.733 atau $73.3 \%$, ini menunjukkan bahwa variabel customer satisfaction yang dapat dipengaruhi oleh variable brand image dan e-service quality adalah sebesar $73.3 \%$. Sedangkan sisanya sebesar 0,367 atau $36.7 \%$ dipengaruhi oleh variabel yang lain. 


\section{Pembahasan}

Berdasarkan hasil penghitungan melalui SPSS versi 22.0 terlihat bahwa brand image dan e-service quality memiliki hubungan yang signifikan terhadap customer satisfaction. Hal tersebut terlihat dari hasil uji $t$ variabel brand image $(\mathrm{X} 1)$ terhadap customer satisfaction $(\mathrm{Y})$ menunjukkan nilai signifikan $0.000<0.05$. Karena sig $<\mathrm{a}$, maka dapat disimpulkan bahwa Ho diterima dan Ha ditolak artinya koefisien regresi pada variabel brand image signifikan. Artinya brand image secara parsial (individu) berpengaruh terhadap customer satisfaction. Sedangkan hasil uji t variabel E-Service Quality (X1) terhadap customer satisfaction $(Y)$ menunjukkan nilai signifikan $0.000<$ 0.05. Karena sig < a, maka dapat disimpulkan bahwa Ho ditolak dan Ha diterima, artinya koefisien regresi pada variabel brand image signifikan. Artinya brand image secara parsial (individu) berpengaruh terhadap customer satisfaction.

Perhitungan tersebut juga diperkuat dengan hasil uji simultan yang menunjukkan bahwa nilai $\mathrm{F}$ hitung sebesar 136.595 sedangkan nilai $F$ tabel sebesar 3,09 maka dapat diketahui nilai $F$ hitung $136.595>F$ tabel 3,09 dan nilai probabilitas signifikan 0,000 lebih kecil dari 0,05. Maka model regresi ini dapat dipakai untuk customer satisfaction. Dengan kata lain dapat dikatakan bahwa variabel brand image dan e-service quality berpengaruh signifikan secara bersama-sama (simultan) terhadap variabel customer satisfaction.

Berdasarkan paparan tersebut dapat disimpulkan bahwa brand image berpengaruh secara signifikan terhadap customer satisfaction. Hal tersebut sejalan dengan respon yang positif dan tingkat kepuasan yang ditunjukkan oleh responden terhadap produk yang ditawarkan oleh Bukalapak. Dalam segi kualitas service atau layanan, Bukalapak pun memberikan layanan yang baik menurut responden. Hal tersebut juga terlihat dari banyaknya customer yang menggunakan jasa bukalapk dalam melakukan transaksi jual beli.

\section{Kesimpulan}

Berdasarkan hasil penelitian ini, maka dapat diambil beberapa kesimpulan. Pertama, Brand Image berpengaruh secara signifikan terhadap Customer Satisfaction Bukalapak. Kesimpulan tersebut sekaligus menjawab hipotesis penelitian pertama, dan sesuai dengan pendapat yang dikemukakan oleh Kurniawati, dkk (2014) bahwa semakin baik Brand Image maka semakin tinggi Customer Satisfaction, dan semakin buruk Brand Image maka semakin rendah pula Customer Satisfaction. Kesimpulan ini sesuai pula dengan penelitian terdahulu oleh Christian Lasander (2013) dan penelitian Muhammad Ehsan Malik, Muhammad Mudasar Ghafoor, Hafiz Kashif lqbal (2012).

Kedua, E-Service Quality berpengaruh secara signifikan terhadap Customer Satisfaction Bukalapak. Kesimpulan tersebut sekaligus menjawab hipotesis penelitian kedua, dan sesuai dengan pendapat Laurent (2016) bahwa semakin baik E-Service Quality yang diberikan perusahaan kepada pelanggan maka Customer Satisfaction semakin tinggi. Kesimpulan ini sesuai pula dengan penelitian terdahulu oleh I Made Stevana Adi Santhika Sudirman (2010) dan penelitian Hansel Jonathan (2013).

Penelitian ini masih mempunyai sejumlah keterbatasan. Pertama penelitian ini hanya mengunakan sedikit variabel independen. Kedua metoda pengolahan data sangat sederhana. Ketiga sampel yang di gunakan masih terbatas. Dengan demikian untuk peneliti berikutnya disarankan untuk menggunakan variabel independen yang lebih banyak dan variabel mediasi yang dapat di gunakann sebagai variabel yang dapat memberikan ketegasan dalam menjelaskan hubungan variabel independen dan variabel dependen. Demikian juga agar sampel yang digunakan leboh banyak sehingga pengolahan data bisa menggunakan analisis jalur atau SEM.

\section{Daftar Pustaka}

Cohen, L., Manion, L., \& Morrison, K. (2007). Research methods in education (6 $6^{\text {th }}$ ed.). New York : Routllege Falmer.

Hansel Jonathan. 2013. Analisis Pengaruh E-Service Quality Terhadap Customer Satisfaction yang Berdampak Pada Customer Loyalty PT. Bayu Buana Travel Tbk, Journal the Winners, Vol. 14, No. 2, Hal 1-8.

I Made Stevana Adi Shantika. 2010.Pengaruh Kualitas Layanan Online Terhadap Kepuasan, Komitmen, dan Loyalitas Nasabah dalam Penggunaan Internet Banking di Denpasar. Master Thesis. Fakultas Ekonomi Universitas Udayana, Denpasar.

Kotler, dan Amstrong. (2008). Prinsip-prinsip Pemasaran. Edisi 12, jilid 1. Jakarta : Erlangga. 
Kotler, Philip. (2005). Manajemen pemasaran Jilid 1 dan 2. Jakarta : PT Indeks Kelompok Gramedia.

Kurniawati, D., Suharyono dan Andriani, K. 2014. Pengaruh citra merek dan kualitas produk terhadap kepuasan dan loyalitas pelanggan (Studi pada pelanggan KFC Cabang Kawi Malang). Jurnal Administrasi Bisnis.14 (2): $1-9$

Laurent, F., 2016, "Pengaruh E-Service Quality terhadap Loyalitas Pelanggan GOJEK melalui Kepuasan Pelanggan", Agora, Vol 4

Lasander, C. (2013). Citra merek, kualitas produk, dan promosi pengaruhnya terhadap kepuasan konsumen pada makanan tradisional (survey pada industry rumah tangga dodol daging pala audia di Tahuna Kab. Sangihe). Jurnal EMBA, 1(3), $284-293$.

Laudon, K.C. \& Laudon, J.P. (2008). Sistem informasi manajemen : terjemahan Chriswan Sungkono dan Machmudin Eka P. edisi 10. Jakarta : Salemba Empat.

Lupiyoadi dan Hamdani. (2006). Manajemen pemasaran jasa edisi kedua. Jakarta : Salemba Empat.

Lupiyoadi, R. (2004). Manajemen pemasaran jasa : teori dan praktek. Jakarta : Salemba Empat.

Lovelock, Christopher. (2010). Pemasaran Jasa. Jakarta : Erlangga.

Malik, M.E. et.al. (2012). Impact of Brand Image, Service Quality and price on customer satisfaction in Pakistan Telecommunication sector. International Journal of Business and Social Science, 3 (23). 123 - 129.

Muhammad Ehsan Malik, Muhammad Mudasar Ghafoor, Hafiz Kashif Iqbal. (2012). Impact of Brand Image, Service Quality and price on customer satisfaction in Pakistan Telecommunication sector.International Journal of Business and Social Science, 3(23).

Peter, J. Paul \& Olson, Jerry. (2013). Perilaku konsumen dan strategi pemasaran, edisi 9 buku 2. Jakarta : Salemba Empat.

Sarwoko. (2007).Statistik inferensi untuk ekonomi dan bisnis. Yogyakarta : Penerbit Andi.

Sulianta. F. (2012). Smart online marketer. Yogyakarta : Penerbit Andi.

Top Brand Award. (2018). [online]. Diakses dari https://www.topbrand-award.com/. 